\title{
Effect of Dye Absorption Time on the Performance of a Novel 2- HNDBA Sensitized ZnO Photo anode Based Dye-Sensitized Solar Cell
}

\author{
Shital S. Rakhunde, ${ }^{1}$ Kisan M. Gadave, ${ }^{1, *}$ Dnyaneshwar R. Shinde ${ }^{1}$ and Pankaj K. Bhujbal ${ }^{2}$
}

\begin{abstract}
In the present study, dye-sensitized solar cells (DSSCs) were fabricated using novel [(2-hydroxy-1-naphthyl) diazenyl] benzoic acid (2-HNDBA) dye. The effect of dye absorption time on the performance of DSSCs was studied. The doctor blade method was employed to prepare the $\mathrm{ZnO}$ seed layer. The structural, morphological and optical properties of the ZnO photoanode were studied systematically. The syntesized ZnO was found to be of hexagonal wurtzite structure. The 2-HNDBA sensitized zinc oxide based DSSCs have been studied for its photoresponse at the dye absorption time from $60-240$ min. The fabricated DSSC prepread at 60 min dye absorbtion time was found to exibit a fill factor and a photo conversion efficiency of 0.44 and $1.09 \%$, respectively. As the preparing time increases to $120 \mathrm{~min}$, the respective parameters increase to 0.53 and $2.08 \%$ at $120 \mathrm{~min}$. However, on further increasing the dye absorbtion time, the fill factor and photo conversion efficiency are reduced to 0.51 , and $1.69 \%$. Thus, $120 \mathrm{~min}$ dye absorbtion time has been found to be the optimized dye absorption time for novel 2 HNDBA dye-sensitized ZnO photoanode based DSSCs.
\end{abstract}

Keywords: Zinc oxide, 2-HNDBA dye; DSSC; Dye absorption time.

Received: 28 August 2020; Accepted: 21 November 2020.

Article type: Research article.

\section{Introduction}

Nowadays, the energy demand is rising in the world from the last four decades and reaches up to the rate growth at $1.8 \%$ per year. ${ }^{[1]}$ Generally, energy is divided into renewable and nonrenewable resources. ${ }^{[2]}$ Renewable energy is energy generated from sources like ocean, hydropower, wind, biomass, geothermal resources, hydrogen, and solar energy. ${ }^{[1]}$ Solar energy is directly used as heat energy or conversion from sunlight into electricity directly as well as indirectly. ${ }^{[3,4]}$ The sun is approximately $3 \times 10^{24} \mathrm{~J}$ per year radiation, which is ten times current energy demand. ${ }^{[5,6]}$ Solar electricity is produced from the conversion of solar radiation into direct current electricity using semiconductors in photovoltaic devices by photovoltaic effects. ${ }^{[3]}$ It produced clean, cheap, safe, high efficiency, and good stability. ${ }^{[7]}$ Photovoltaic techniques are divided into first, second and third generation. ${ }^{[8]}$ The first third-generation DSSCs were reported in 1991 by Gratzel et

\footnotetext{
${ }^{I}$ Prof. Ramkrishna More Arts, Commerce and Science College Akurdi, Pune, India

${ }^{2}$ Advanced Physics Laboratory Department of Physics, Savitribai

Phule Pune University, Pune, India

* Email: kmgadave@gmail.com (K. M. Gadave)
}

al. ${ }^{[9]}$ The current thin films solar cell and crystalline and amorphous silicon solar cells are used to convert solar energy into electricity. However, there are some restrictions such as toxicity, high production time, production cost, and types of substrates used for the fabrication device. This has attracted researchers to find its alternatives. A dye-sensitized solar cell (DSSC) is the third generation solar cell. It is one of the most promising solar cell devise than crystalline solar cells and thinfilm solar cell devices due to their simple manufacturing, high power conversion efficiency, low production cost, and nontoxicity. $^{[10]}$ In DSSCs, metal oxide semiconductor has good stability under irradiation in liquid solution but it cannot absorb visible light due to its wide-bandgap. If these types of materials are sensitized with a photosensitizer such as dyes then they work as photo-anode in DSSC's. The photosensitizer in the adsorbed form on the metal oxide undergoes electronic excitation on irradiation with visible radiations. The excited state electron from lowest unoccupied molecular orbital (LUMO) of the dye is then injected into the conduction band (CB) of the meatal oxide. In 1988, Michael Gratzel and co investigators was invented the $\mathrm{Ru}(\mathrm{II})$ based dye as promising sensitizer in photoelectrochemical cells. ${ }^{[11]}$ The conversion of visible light to electrical energy depends on nature's principle of photosynthesis. DSSC consists of photo electrode made up of conducting glass plate and coated with porous nano- 
crystalline wide bandgap semiconductor on which dye is adsorbed. A counter electrode is platinum or graphite coated on glass. Electrolyte solution is placed between two electrodes which contains redox couple. The dye on semiconductor absorbs light and eject electron into $\mathrm{CB}$ of semiconductor and this electron flows through external circuit thus, electromotive force (EMF) is generated in a cell. The electrolyte receive electron from cathode while oxidized dye receive electron from the electrolyte and regenerated. ${ }^{\left[{ }^{12,13]}\right.}$ The function of dye is similar to chlorophyll in plants. Recently, $\mathrm{TiO}_{2}$ nanoparticles (TNPs) are usually used as photo anode materials for the fabrication of DSSCs because of their interesting properties like wide band gap, high surface area for dye adsorption and high stability as photo anode. However, its low electron mobility and transport properties are responsible to find out alternatives to $\mathrm{TiO}_{2}{ }^{[14]}$

$\mathrm{ZnO}$ is one of the promising alternatives to $\mathrm{TiO}_{2}$ due to its low cost, easy availability, and simplicity in preparation using simple chemical methods. Its energy-band structure is similar to that of $\mathrm{TiO}_{2}$. It possesses a higher electron mobility than $\mathrm{TiO}_{2}{ }^{\left[{ }^{[15-16]}\right.} \mathrm{ZnO}$ is II-VI compound semiconductor material having a direct bandgap and a large excitation energy of $\sim 3.37$ $\mathrm{eV}$ and $\sim 60 \mathrm{meV}$, respectively at room temperature. ${ }^{[17-20]} \mathrm{C}$. For example, Wang et al. ${ }^{[21]}$ improved the dye-sensitized solar cells (DSSCs) with a $\mathrm{ZnO}$ nano-flower photo-anode. $\mathrm{ZnO}$ is an II-VI semiconductor and the bandgap is $3.37 \mathrm{eV}$. ZnOnano-flower film is fabricated by the hydrothermal deposition and it increases the dye loading and harvesting. Good electron conductivity rod of photo-anode efficiency is $1.9 \%$. Zinc chloride aqueous solution was used to obtain seed layer of $\mathrm{ZnO}$ on fluorine doped tin oxide (FTO) plate. Aqueous solution of zinc acetate di-hydrate was used to obtain nanorods and nano-flowers on the seed layer. I-V characteristic of cell was studied using $\mathrm{N}_{719}$ dye. For the cell having flower like $\mathrm{ZnO}$ the fill factor was $53 \%$ and efficiency was $1.9 \%$. While for rod like $\mathrm{ZnO}$ fill factor was $36 \%$ and efficiency was found $1.0 \%$. The $\mathrm{ZnO}$ nano-flower is more efficient than the nanorod.

Among various parameters like photoanode morphology, film thickness, and dye adsorption time, dye absorption time is one of the most important parameters influencing the performance of the fabricated DSSCs. The porous nature of the photoanode is responsible for the absorption of dye molecules within the $\mathrm{ZnO}$ surface area. As the porosity of film increases, there is an increase in the dye absorption rate hence light absorption gets enhanced. The result in the photoconversion efficiency of the device will be improved. ${ }^{[22]}$ Numerous research reports have reported the effect of dye adsorption time on the performance of the DSSCs. For example, Khadtare et al. reported $\mathrm{ZnO} / \mathrm{TiO}_{2}$ photoanode with Rose Bengal dye and $\mathrm{N}_{719}$ dye as sensitizer, ${ }^{[23-26]}$ dye adsorption mechanisms in $\mathrm{TiO}_{2}$ films, and their effects on the photodynamic and photovoltaic properties in DSSCs. ${ }^{[27-28]}$

In this research work, DSSC photoanode was deposited using commercially $\mathrm{ZnO}$ nanoparticles. A seed layer of $\mathrm{ZnO}$ deposited on FTO by a simple low-cost doctor blade technique.
The prepared $\mathrm{ZnO}$ photoanode was analyzed by using X-ray diffraction (XRD), UV-Visible absorption spectroscopy, and scanning electron microscope (SEM). The 4-[(2-hydroxy-1naphthyl) diazenyl] benzoic acid (2-HNDBA) photosensitizer was synthesis by a simple chemical method. The prepared $\mathrm{ZnO}$ photoanodes were sensitized by the freshly prepared lowcost 2-HNDBA dye. In this work, the novel 2-HNDBA dye was used for the fabrication of DSSC. This dye was not reported till the date as a sensitizer in ZnO based DSSC. The effect of dye absorption time on the performance of $\mathrm{ZnO}$ based DSSC was systematically studied.

\section{Experimental}

\subsection{Materials and Methods}

The following materials and methods are used for the fabrication of DSSCs,

Materials: Zinc acetate (Sigma Aldrich), sodium hydroxide (Thomas Baker), $\mathrm{ZnO}$ Nanopowder (Sigma Aldrich), ethylcellulose (SDFCL), $\alpha$-terpineol (HPCL), acetylacetone (SRL), p-aminobenzoic acid, $\mathrm{HCl}$, etc.

Methods: (a) CBD Method for deposition of a compact layer. (b) Doctor blade method for deposition of the seed layer.

\subsection{Synthesis of $\mathrm{ZnO}$ barrier layer}

The barrier layer of $\mathrm{ZnO}$ was synthesized using $0.01 \mathrm{M}$ zinc acetate in $100 \mathrm{~mL}$ ethanol. $0.05 \mathrm{M}$ sodium hydroxide was added dropwise in the above solution until just white turbidity appeared. The cleaned FTO plate was dipped into this solution and dried. This process was repeated 10 times, and then the film was dried on a hot plate at $250^{\circ} \mathrm{C}$ for 30 minutes.

\subsection{Preparation of $\mathrm{ZnO}$ seed layer}

The thick layer of zinc oxide was prepared on the barrier layer by doctor blade technique. ${ }^{[29-30]} 10 \mathrm{~g}$ of zinc oxide powders were mixed with methylcellulose ( $30 \mathrm{wt} \%$ metal oxide) and ground for $1 \mathrm{~h}$ in mortar and pestle. This mixture was transferred into a screw cap test tube and ethanol was added (approx $25 \mathrm{~mL}$ ) to form a paste. This paste was sonicated for 4 cycles (each cycle was of 15 minutes.). After the formation of uniform suspension, $1.5 \mathrm{~mL}$ acetylacetone and $3.5 \mathrm{~mL} \alpha$ terpineol were added to it, and the paste was stirred with a glass rod and then again sonicated for 2 cycles of 15 minutes. Then FTO was covered with the scotch tape (double layer) and the central $1 \mathrm{~cm}$ portion was kept open. Then the drop of paste was placed on the central portion of the plate (at one end) and the uniform layer was obtained by spreading it with another glass plate. The plate was dried at $60{ }^{\circ} \mathrm{C}$ in a hot air oven and then another layer was applied similarly. The plate was dried at $60{ }^{\circ} \mathrm{C}$ again for 30 minutes, then the scotch tape was removed and the plate was annealed at $450{ }^{\circ} \mathrm{C}$ for $1 \mathrm{~h}$ where the heating rate of the furnace was adjusted $10{ }^{\circ} \mathrm{C}$ per minute.

\subsection{Synthesis of dyes}

The 2-HNDBA dye was prepared as reported by Mann et al. ${ }^{[31]}$ The first step of preparation of dye is the diazotization of $\mathrm{p}$ aminobenzoic acid. When $\mathrm{HCl}$ was added to $\mathrm{NaNO}_{2}$ solution 
then $\mathrm{HNO}_{2}$ was formed. $\mathrm{HNO}_{2}$ reacted with p-aminobenzoic acid to form diazonium salt (Fig. 1.).

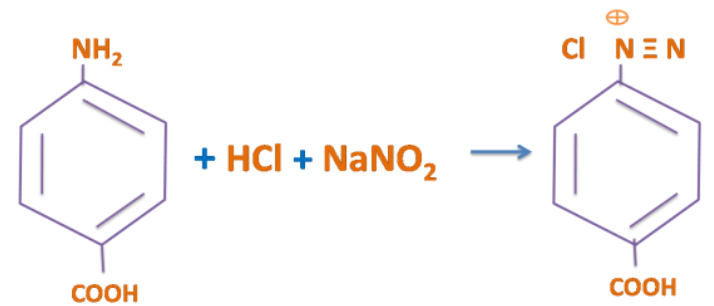

Fig. 1 Reaction of diazonium salt of p-aminobenzoic acid to form 2-HNDBA.

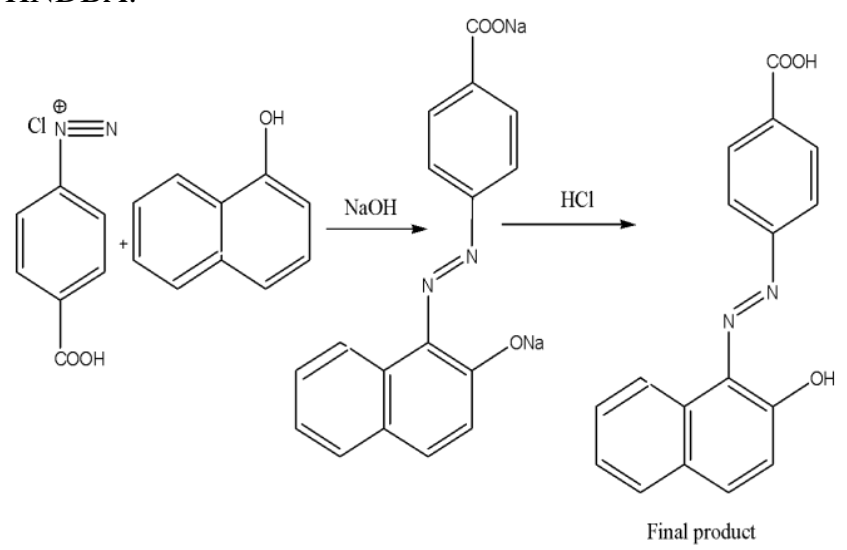

Fig. 2 Reaction for $\beta$-naphthol 1-Azo p-ammino benzoic Acid Dye.

The diazonium salt of p-aminobenzoic acid then reacted with the alkaline solution of beta naphthol (1:1 molar proportion) to form the red-colored sodium salt of azo dye. The salt on acidification gave insoluble orange-colored dyestuff, which was recrystallized from ethanol and used in the present study (Fig. 2). The percent practical yield of the dye was $70.76 \%$ and the melting point of this dye was $187^{\circ} \mathrm{C}$. Purity of dye was checked by thin layer chromatography (TLC) method. TLC showed a single spot on plate having $\mathrm{R}_{f}$ (retardation factor) value 0.71 . It matches with the reported value. ${ }^{[31]}$ Therefore, we concluded that the final product obtained is the expected dye molecule i.e. 4-[(2-hydroxy-1naphthyl) diazenyl] benzoic acid dye. The IUPAC name of synthesized azo dye is 4-[(2-hydroxy-1-naphthyl) diazenyl] benzoic acid. The dye is synthesized concerning its structure. It is reported that when the dye molecule is planar, consists of a binding group, and has conjugated double bonds, then it gives a good efficiency in DSSC. ${ }^{[32-34]}$ In the synthesized molecule, $-\mathrm{COOH}$ and $-\mathrm{OH}$ can act as a binding group to oxide while two benzene rigs are in conjugation with each other through the azo bond. 4-[(2-hydroxy-1-naphthyl) diazenyl] benzoic acid dye is abbreviated as 2-HNDBA.

The advantages of 2-HNDBA dye are the following. It is cheap and simple in the process. This means that the dye is cost-efficient. It is an environment friendly in nature. It is easily soluble in alcohol like methanol, ethanol, etc. It shows a maximum absorption at $488 \mathrm{~nm}$ (Visible Region). The above advantages make the 2-HNDBA dye as an efficient sensitizer for DSSCs.

\subsection{Sensitization of dye}

The 2-HNDBA dye solutions were prepared using $50 \mathrm{mg}$ of prepared dye in $25 \mathrm{~mL}$ methanol. It was completely dissolved to form a clear solution. $\mathrm{ZnO}$ coated films were immersed in the dye solution for $60,120,180$, and 240 minutes and taken out. Then films were dried in a dryer at $60{ }^{\circ} \mathrm{C}$ for 10 minutes.

\subsection{Preparation of Counter Electrode}

The counter electrode was prepared using graphite powders, which were prepared by applying a thin coat of graphite on the FTO conducting plate (HB pencil lids were used as a source of graphite). The uniformity was checked by checking the conductivity of the film, which was around 3-5 Ohm only. These electrodes with carbonaceous materials have various advantages such as high electron conductivity, decreased corrosion resistance, and minimum cost required than the platinum electrode.

\subsection{Preparation of electrolyte solution}

Polyiodide was used as an electrolyte in the present study. It is an aquesou solution. $0.5 \mathrm{M}$ potassium iodide and $0.05 \mathrm{M}$ iodine were prepared in $100 \mathrm{~mL}$ distilled water. The solution was stirred well and $\mathrm{pH}$ was maintained to 7 .

\subsection{Construction of dye-sensitized solar cell}

The DSSSC devices were fabricated using $\mathrm{ZnO}$ based photoanode, 2-HNDBA dye, poly-iodide as an electrolyte, and graphite coated FTO substrate as the counter electrode. Two drops of electrolyte were placed on $\mathrm{ZnO}$ film in the spacer cavity and the cathode was placed on it. The cathode and anodes were held tightly with the help of clamps. The electrical connections were established from cathode and anode with the help of alligator's clips and wires. This prepared device was characterized by photovoltaic measurement.

\section{Characterizations}

The deposited $\mathrm{ZnO}$ photoanodes were characterized by XRD, UV-Visible absorption spectroscopy, SEM, energy dispersive $\mathrm{X}$-ray spectroscopy (EDS), etc. for the confirmation of structural optical and morphological properties. The structural properties of the $\mathrm{ZnO}$ photoanode were performed to investigate the crystal structure using an X-ray diffractometer (model Bruker D8 with $\mathrm{CuK} \alpha$ radiation of wavelength 1.54 $\left.A^{\circ}\right)$.

The optical properties of 4-[(2-hydroxy-1-naphthyl) diazenyl] benzoic acid photosensitizer sensitized $\mathrm{ZnO}$ films were studied by JASCO V-670 UV-Vis spectrophotometer. The scanning electron microscopy was used to investigate the 
Table 1. Unit cell parameters of the $\mathrm{ZnO}$ photoanode.

\begin{tabular}{llllll}
\hline $\mathbf{2 \theta}$ & $\mathbf{d}(\mathrm{nm})$ & $\begin{array}{l}\text { Peak } \\
\text { intensity }\end{array}$ & {$[\mathbf{h k l}]$} & Unit cell parameters & \\
\hline 31.86 & 2.807 & 65.39 & {$[100]$} & & Observed \\
34.49 & 2.599 & 47.36 & {$[002]$} & A & $3.2411 \AA$ \\
36.34 & 2.471 & 100.0 & {$[101]$} & C & $5.1963 \AA$ \\
47.62 & 1.908 & 17.82 & {$[102]$} & Unit cell volume & $4.272 \times 10^{-23} \mathrm{~cm}^{3}$ \\
56.68 & 1.623 & 34.00 & {$[110]$} & Dx & $5.752 \mathrm{~g}^{3} \mathrm{~cm}^{3}$ \\
62.9 & 1.477 & 25.02 & {$[103]$} & & $35.87 \mathrm{~nm}^{\circ}$ \\
66.45 & 1.406 & 5.42 & {$[200]$} & Average crystal size & \\
68.02 & 1.378 & 23.09 & {$[112]$} & & \\
69.16 & 1.358 & 11.94 & {$[201]$} & & \\
72.61 & 1.301 & 2.54 & {$[004]$} & & \\
77.03 & 1.237 & 3.50 & {$[202]$} & & \\
\hline
\end{tabular}

surface morphology of the 4-[(2-hydroxy-1-naphthyl) diazenyl] benzoic acid synthesized $\mathrm{ZnO}$ photoanodes by using JSM-7600F. The photovoltaic performance of 4-[(2-hydroxy1-naphthyl) diazenyl] benzoic acid sensitized $\mathrm{ZnO}$ films was studied under the illuminated conditions by using a Keithley 2400 source meter and solar simulator (ENLITECH Model SS-F5-3A) with an incident light intensity $100 \mathrm{~mW} / \mathrm{cm}^{2}$.

\section{Results and Discussion}

\subsection{Purity of $\mathrm{ZnO}$}

The purity of zinc oxide is calculated using chemical methods, where $\mathrm{Zn}$ (II) content was analyzed by complex metric titration. It is agreed with the molecular formula of zinc oxide.

\subsection{X-ray diffraction Analysis}

Fig. 3 shows the XRD pattern of $\mathrm{ZnO}$. All peaks match with the Standard JCPDS card no. 36-1451, having $2 \Theta$ equal to $=$ $31.86,34.49,36.34,47.62,56.68,62.9,66.45,68.02,69.16$, 72.61 and 77.03 corresponding to $(100,(002),(101),(102)$, (110), (103), (200), (112), (201), (004) and (202)). This also confirms the hexagonal crystal structure (Patil et. al, 2010). ${ }^{[35-}$ ${ }^{39]}$ The extra peaks are not observed, which confirm that $\mathrm{ZnO}$ is pure having a single crystalline phase. ${ }^{[40]}$ The average particle size of powder $\mathrm{ZnO}$ was $35.87 \mathrm{~nm}$ estimated by using the Debye-Scherer formula.

The structural parameter a and $\mathrm{c}$ were calculated from the interplanar distance lattice constants and it was 3.241 and $5.196 \AA$. The unit cell volume was calculated from the lattice constants a and $\mathrm{c}$ and found to be $4.272 \times 10^{-23} \mathrm{~cm}^{3}$. For the determination of $\mathrm{ZnO}$ by using the unit cell volume, $\mathrm{X}$-ray density (Dx), and it was found to be $5.752 \mathrm{~g} / \mathrm{cm}^{3}$. These values are in good agreement with previously reported values of Zinc Oxide have hexagonal unit cell structure. ${ }^{[5,6,41]}$

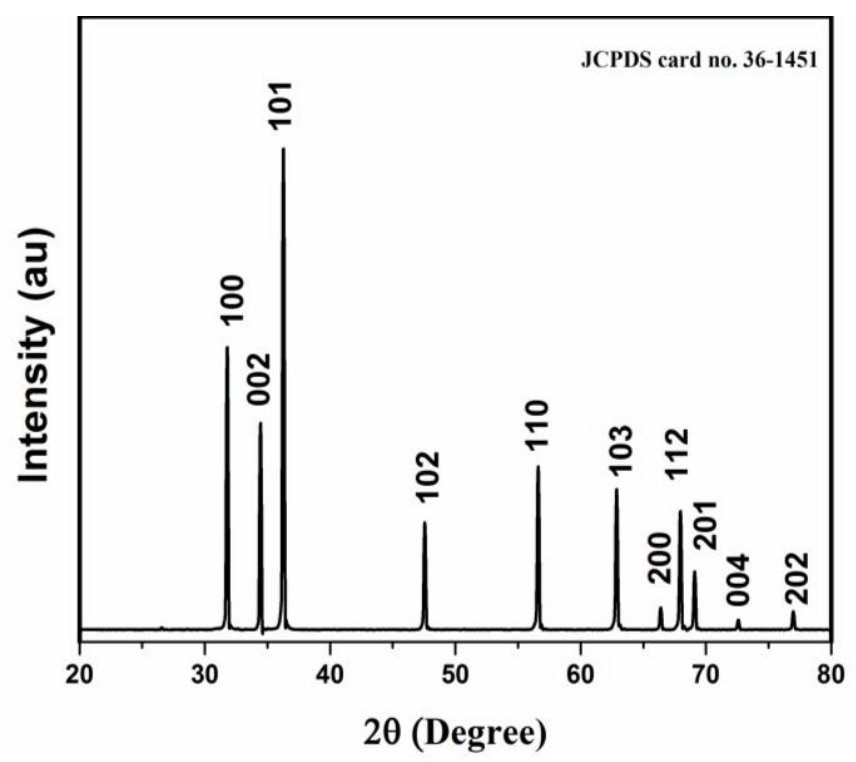

Fig. 3 XRD patterns of the $\mathrm{ZnO}$ photoanode.

\subsection{Optical Properties}

The optical properties of the $\mathrm{ZnO}$ photoanode were measured by using JASCO UV-Vis. Spectrometer within the range of 200 to $800 \mathrm{~nm}$. Fig. 4. shows the optical absorption of the 2HNDBA dye. UV-Visible absorbance spectra of synthesized 
Table. 2 Photovoltaic parameters of 2-HNDBA dye-sensitized ZnO photoanode based DSSCs for various dye absorption time.

\begin{tabular}{ccccc}
\hline & \multicolumn{4}{c}{ Photovoltaic parameters } \\
\cline { 2 - 5 } Dye Adsorption Time (minutes) & 60 & 120 & 180 & 240 \\
Voc (V) & 0.332 & 0.347 & 0.346 & 0.350 \\
ISC (mA/cm $\left.{ }^{2}\right)$ & 1.927 & 2.896 & 2.488 & 0.51 \\
FF & 0.44 & 0.53 & 1.71 & 1.69 \\
Efficiency (\%) & 1.09 & 2.08 & & 1.51 \\
\hline
\end{tabular}

dye were recorded where dye was dissolved in methanol at the appropriate concentration. The absorbance spectra of the dye in methanol show a maximum absorbance at $488 \mathrm{~nm}$.

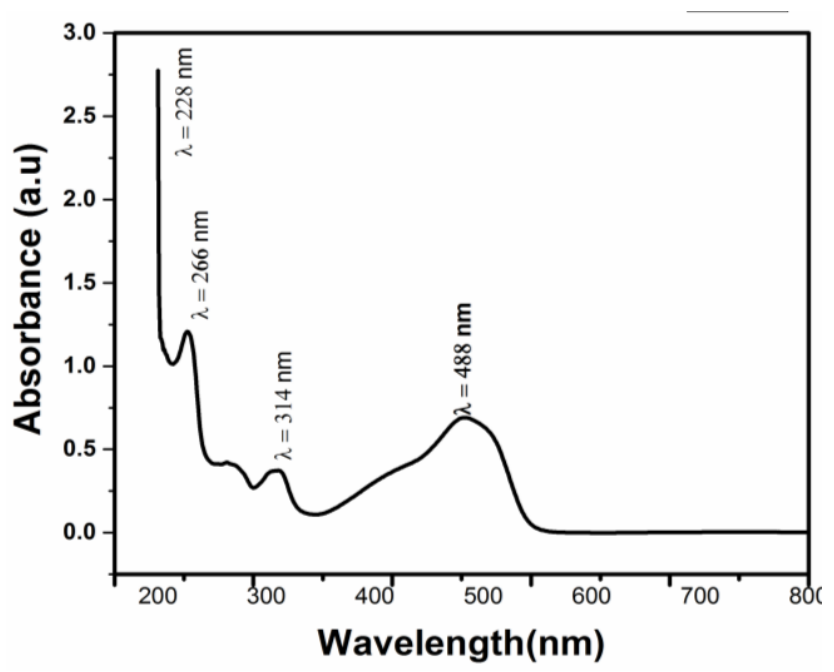

Fig. 4 Absorbance spectra of 2-HNDBA dye.

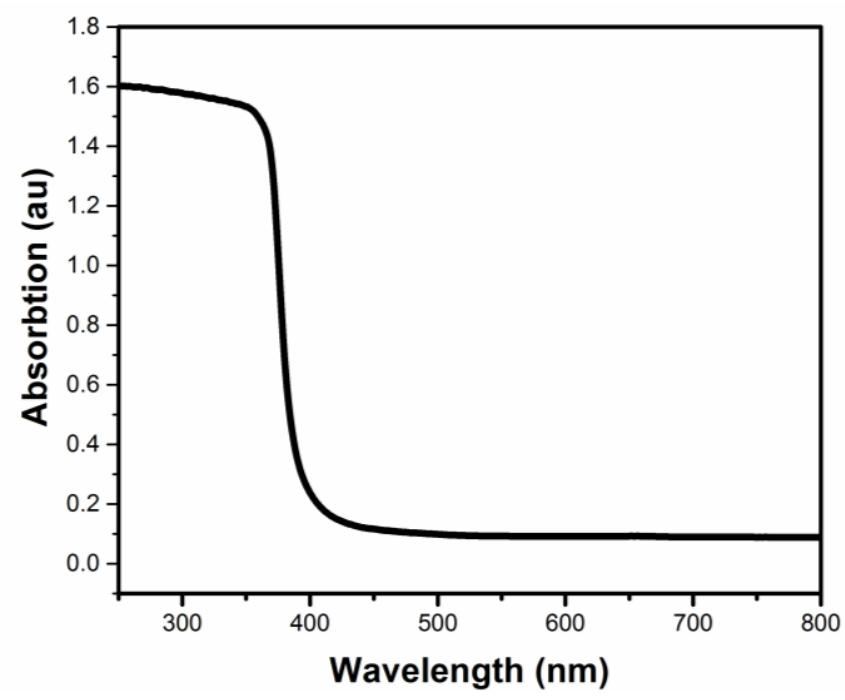

Fig. 5 Absorbance spectra of the $\mathrm{ZnO}$ photoanode.

Fig. 5 shows the optical absorption of the $\mathrm{ZnO}$ photoanode. The bandgap of $\mathrm{ZnO}$ photoanode was obtained from diffuse reflectance spectra in absorbance mode and recorded in the solid-state. Fig. 6 shows the tauc plot of the $\mathrm{ZnO}$ thin film. The band gaps of $\mathrm{ZnO}$ were found to $3.24 \mathrm{eV}$. The absorption of energy at the bandgap corresponds to the electronic excitation of an electron from a valence band to the gaps of metal oxide that are in good correlation with the bandgap reported for this oxide. ${ }^{[42,43]}$

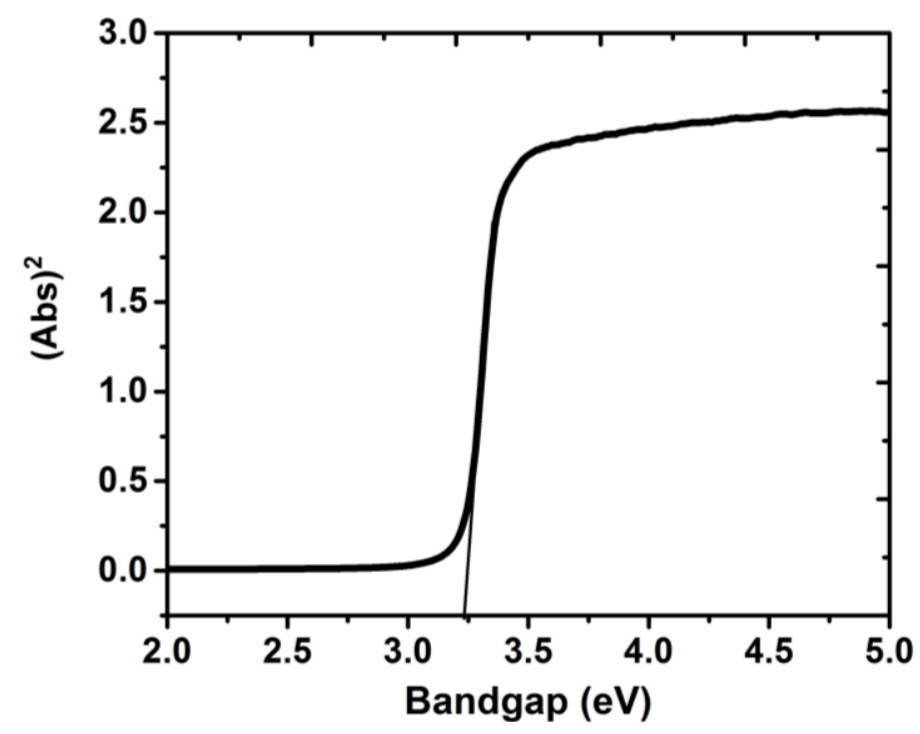

Fig. 6 Tauc plot of the $\mathrm{ZnO}$ photoanode.

The mass loading (or dye uptake $\mathrm{mol} / \mathrm{gm}$ ) of the 2HNDBA dye is determined from the absorption spectrum of the dye at various dye adsorption periods. In pure methanol, the dye from the $\mathrm{ZnO}$ film was desorbed and the spectrum was recorded. In Fig. 7., these are presented. The loading of the amount of dye on the $\mathrm{ZnO}$ film was determined from the dye absorption. For 60, 120, 180 and 240 minutes of dye loading time the amount of dye loaded was respectively $0.185,0.223$, $0.244,0.256 \mathrm{mg} / \mathrm{cm}^{2}$.

\subsection{Scanning electron microscopy (SEM) aalysis}

Fig. 8 (a) shows the SEM image of the ZnO barrier layer. We have obtained the barrier layer by chemical deposition method till film is slightly visible on the FTO plate. The thickness of $\mathrm{ZnO}$ barrier layer was approximetly 1.5-2.0 micron. It shows the irregular shape rod-like morphology. The growth orientation of the $\mathrm{ZnO}$ nanorod was perpendicular to the substrate. The particles are not uniform in length and diameter. Fig. 8 (b) shows the SEM images of the $\mathrm{ZnO}$ photoanode prepared by the doctor blade method. The surface morphology played a significant role in dye adsorption. ${ }^{[4]}$ Fig. 5 shows the porous nature of the $\mathrm{ZnO}$ photoanode. It improves the dye absorption rate and thus the photoconversion efficiency of DSSC was enhanced. ${ }^{[44]}$ 


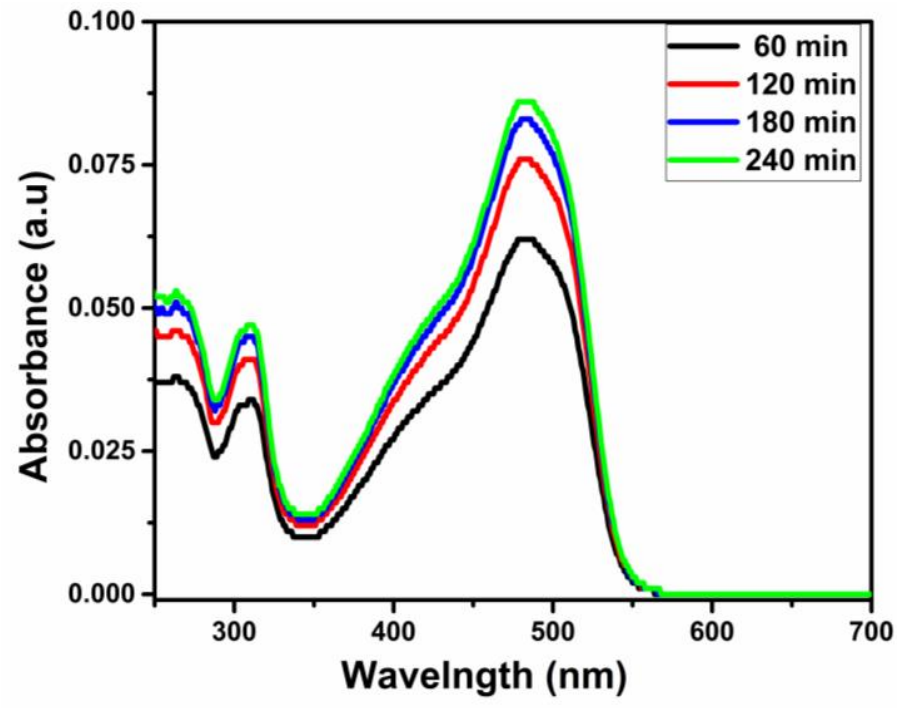

Fig. 7 Absorbance spectra of 2-HNDBA dye for 60, 120, 180 and 240 minutes respectively

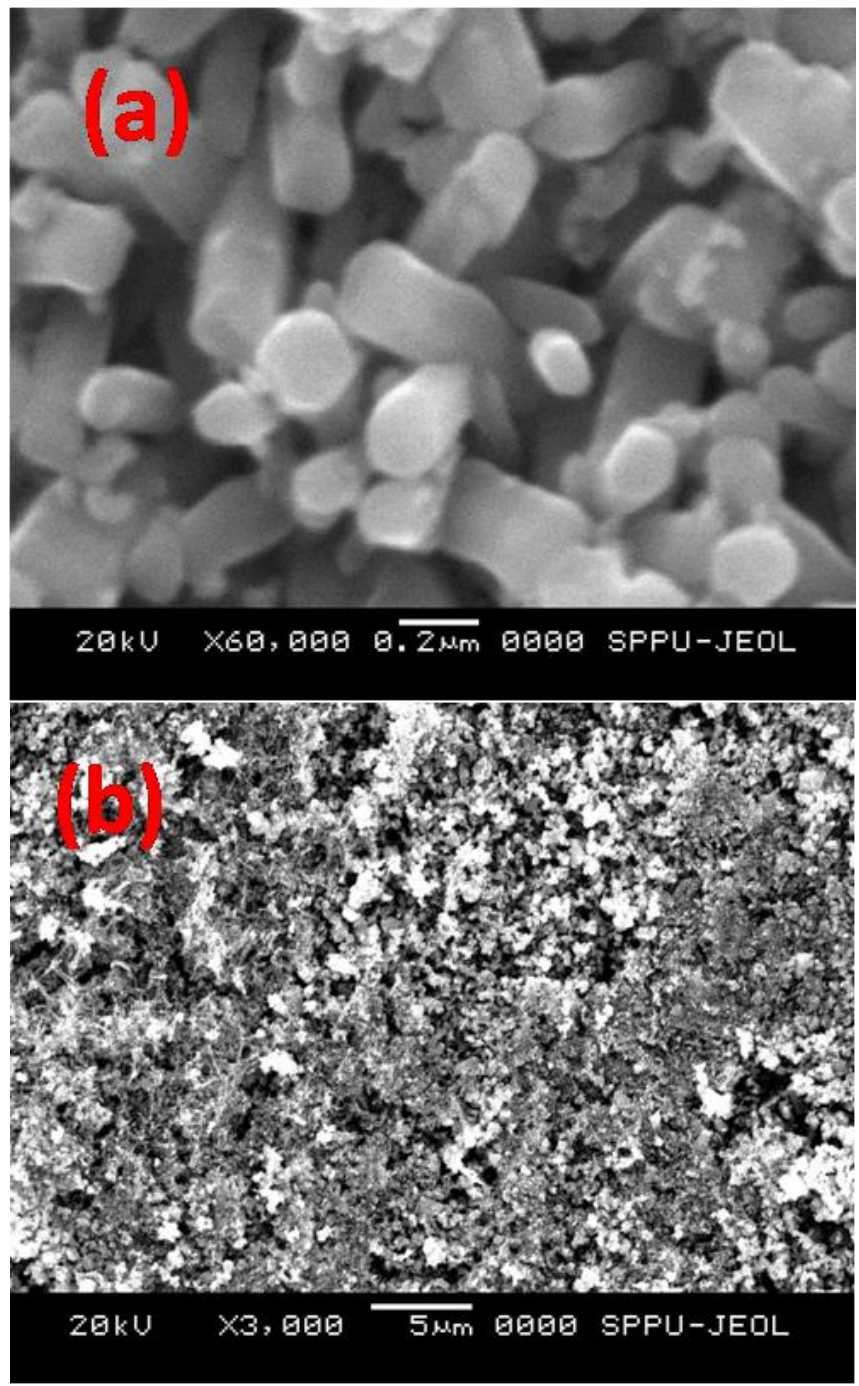

Fig. 8 SEM image of (a) the barrier layer of $\mathrm{ZnO}$ film and (b) $\mathrm{ZnO}$ photoanode (Top view).
Fig. 9 show I-V characteristics DSSCs based on $\mathrm{ZnO}$ photoanode sensitized with 2-HNDBA dye. $\mathrm{ZnO}$ photoanode was sensitized for various time, the adsorption rates $(60,120$, 180 , and $240 \mathrm{~min}$ ) were tested for photovoltaic performance under one sun condition. Similar results on the effect of dye adsorption time on $\mathrm{ZnO} / \mathrm{TiO}_{2}$ photoanode with Rose Bengal dye and $\mathrm{N}_{719}$ dye as sensitizer were obtained by Khadtare et al. ${ }^{[26]}$ The photovoltaic parameters such as $\mathrm{V}_{\mathrm{OC}}$, short-circuit $\mathrm{J}_{\mathrm{SC}}$, fill factor (FF) and photoconversion efficiency $(\eta)$ of DSSCs are discussed in the following paragraph and also summarized in Table 2.

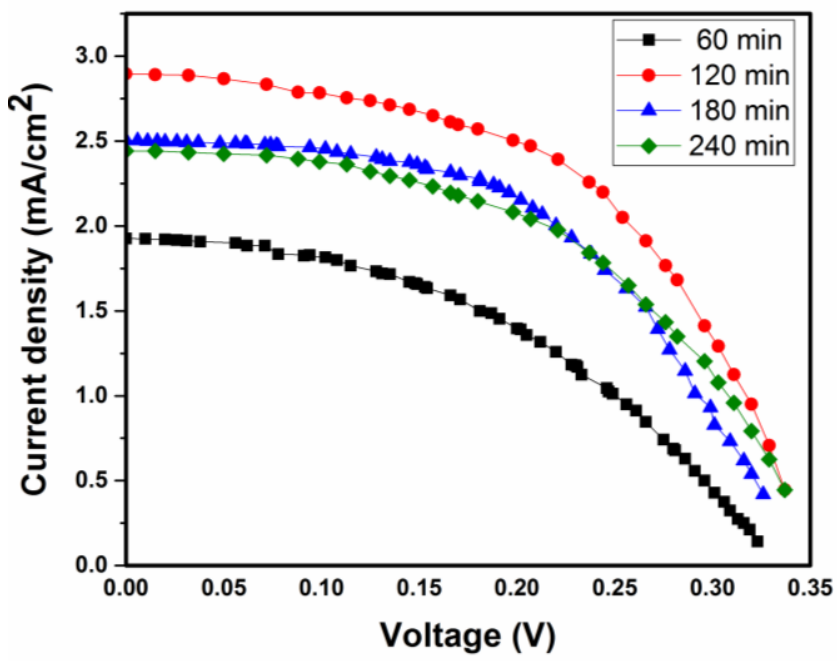

Fig. 9 I-V curve of $\mathrm{ZnO}$ film at different dye adsorption time of 2-HNDBA dye

The $\mathrm{ZnO}$ photoanode sensitized for $60 \mathrm{~min}$ dye absorption time shows a poorer performance than other cells. Since 60 minutes dye absorption time is less for the adsorption of dye on $\mathrm{ZnO}$ and in this time all adsorption sites of $\mathrm{ZnO}$ might not be occupied by the dye molecules. ${ }^{[45]}$ Thus, such cells displayed a lower performance. The photo-conversion efficiency was improved with increasing the dye adsorption time from 60 to 120 minutes. From it is concluded that the adsorption time of 120 minutes is sufficient for occupying all surface adsorption sites on $\mathrm{ZnO}$. The adsorption time less than 120 minutes might not be sufficient to occupy all surface adsorption sites of $\mathrm{ZnO}$ by the dye. Thus, cell with such a photo-anode where dye adsorption time is 120 minutes showed the best performance. Further increasing the dye absorption time to 180- 240 minute, the photoconversion efficiency of the device was reduced slightly. Because multilayer adsorption of the dye created the barrier for the transfer of an electron from dye molecule to $\mathrm{ZnO}$ (Fig. 10.), such barrier reduced the photovoltaic performance of the cell.

\subsection{Photovoltaic measurements}




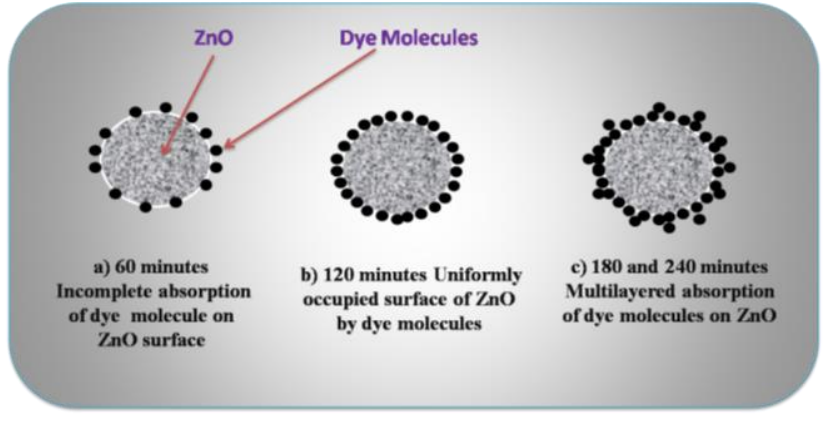

Fig. 10 Effect of dye adsorption time on $\mathrm{ZnO}$ surface.

Thus, the above study confirmed that the cell with 2 HNDBA dye-sensitized for $120 \mathrm{~min}$ dye absorption time shows a high performance as compared to other cells, which show $0.347 \mathrm{~V}$ Voc, fill factor $53 \%$ and overall conversion efficiency of $2.08 \%$. The current study concludes that dye absorption time played an important role on the performance of DSSCs.

\section{Conclusion}

In summary, dye-sensitized solar cells (DSSCs) were successfully fabricated using the low-cost 2-HNDBA dye. $\mathrm{ZnO}$ barrier layer was successfully grown by chemical bath deposition (CBD) method. The doctor blade method was employed to prepare the $\mathrm{ZnO}$ seed layer. The XRD pattern confirmed the hexagonal wurtzite structure of $\mathrm{ZnO}$. The 2HNDBA dye was successfully loaded on a porous $\mathrm{ZnO}$ photoanode at various dye absorption time and studied its photovoltaic properties. 2-HNDBA dye consists of polar functional groups, i.e., $-\mathrm{COOH}$ and $-\mathrm{OH}$ in their structure and planar. Thus, the above study confirmed that the cell with 2HNDBA dye-sensitized for $120 \mathrm{~min}$ dye absorption time shows a high performance as compared to other dye absorption time rates, which shows a Voc of $0.347 \mathrm{~V}$, fill factor $53 \%$ and the overall conversion efficiency of $2.08 \%$. The current study concludes that the dye absorption time played an important role in the performance of 2-HNDBA dye-sensitized DSSCs.

\section{Acknowledgment}

KMG greatly thankful to Prof. Ramkrishna More Arts, Commerce and Science College, Akurdi, Pune, India and Advanced Physics Laboratory, Department of Physics, Savitribai Phule Pune University, Pune, India for experimental and characterization facilities and constant motivation.

\section{Support information}

Not applicable

\section{Conflict of Interest}

There are no conflicts to declare.

\section{References}

[1] S. Saadaoui, M. Youssef, M. Karoui, R. Gharbi, E. Smecca, V. Strano, S. Mirabella, A. Albert, and R. Puglisi, Beilstein J. Nanotechnol., 2017, 8, 287-295, doi: 10.3762/bjnano.8.31.

[2] R. Kumar, A. Umar, G. Kumar, H. Nalwa, A. Kumar, and M.
S. Akhtar, J. Mater. Sci., 2017, 52, 4743-4795, doi: 10.1007/s10853-016-0668-z.

[3] S. M. Shauddin, Ener. Power, 2013, 3, 91-105. doi:10.5923/j.ep.20130306.01.

[4] U. Mehmood, S. Rahman, K. Harrabi, I. Hussein and B. Reddy, Adv. Mater. Sci. Engg., 2014, 12, 974782. doi: 10.1155/2014/974782.

[5] Basic Research Needs for Solar Energy Utilization-Caltech Authors available at (https://authors.library.caltech.edu/8599/1/SE U_rpt05.pdf).

[6] N. Rawal, A. Vaishaly, H. Sharma, B. Mathew, Energy and Pow. Eng. Sci.., 2015, 2(2), 46-52, doi: 10.12966/epes.05.03.2015.

[7] Sayyed, N. Beedri, V. Kadam and H. Pathan, Bull. Mater. Sci., 2016, 3, 1381-1387 doi: 10.1007/s12034-016-1279-7.

[8] A. Zulkifli, T. Kento, M. Daiki, and A. Fujkiki, J. Clean Ene. Techn., 2015, 3, 382-387. doi: 10.7763/JOCET.2015.V3.228.

[9] B. O'Regan and M. Gratzel, Nature, 1991, 353, 737-740, doi: 10.1038/353737a0.

[10] Ganesh, T., H. Nguyen, R. S. Mane, N. K. Dipak V. Shinde, S. S. Bhande, M. Naushad, K. Hui, and S. Han, Dalton Trans., 2014, 43, 11305-11308, doi: 10.1039/C4DT01179A.

[11] F. Bella, C. Gerbaldi, C. Barolo and M. Gratzel, Royal Soc. Chem., 2015, 44, 3431-3473. doi: 10.1039/C4CS00456F.

[12] F. Kong, S. Dai, K. Wang, Adv. Opto Elect., 2007, 1-13, doi: $10.1155 / 2007 / 75384$.

[13] J. Wu, Z. LAN, S. Hao, P. Li, M. Huang, L. Fang, and Y. Huang, Pure App. Chem., 2008, 80, 2241-2258, doi: 10.1351/pac200880112241.

[14] A. N. Kawade, P. K. Bhujbal, A. T. Supekar, H. M. Pathan, and K. M. Sonawane, Optik, 2020, 216, 164968. doi: 10.1016/j.ijleo.2020.164968.

[15] Quintana, Maria, T. Edvinsson, A. Hagfeldt, and G. Boschloo, J. Phy. Chem. C, 2007, 111, 1035-1041, doi: 10.1021/jp065948f.

[16] Gao YF, Nagai M, Chang TC, Shyue JJ, Cryst Growth Des, 2007, 7, 2467-2471, doi: 10.1021/cg060934k.

[17] P. K. Bhujbal, H. M. Pathan and N. B. Chaure, Eng. Sci., 2020, 10, 58-67, doi: 10.30919/es8d1003.

[18] P. K Bhujbal, H. M. Pathan and N. B. Chaure, ES Ener. Envir., 2019, 4, 15-18, doi: 10.30919/esee8c188.

[19] Hui, K. N., K. S. Hui, X. L. Zhang, R. S. Mane, and M. Naushad, Sol. Ener., 2016, 125, 125-134. doi: 10.1016/j.solener.2015.12.002.

[20] X. L. Zhang, K. N. Hui, K. S. Hui, and J. Singh, Mater. Res. Bull., 2013, 48, 1093-1098, doi: 10.1016/j.materresbull.2012.11.104.

[21] Jiang, C. Y., X. W. Sun, G. Q. Lo, D. L. Kwong, and J. X. Wang, App. Phy. Lett., 2007, 90, 263501, doi: 10.1063/1.2751588. [22] Chang, Wei-Chen, C. Lee, W. Yu, and C. Lin, Nano. Res. Lett., 2012, 7, 1-10, doi: 10.1186/1556-276X-7-688.

[23] Imbrogno, Alessandra, R. Pandiyan, A. Macario, A. Bonanno, and M. Ali El Khakani, IEEE J. Photovol., 2019, 9, 1240-1248, doi: 10.1109/JPHOTOV.2019.2922381.

[24] T. Bora, H. Kyaw, S. Sarkar, S. Pal, and J. Dutta, Beilst. J. 
Nanotechnol., 2011, 2, 681-690. doi: 10.3762/bjnano.2.73.

[25] A. Zainal, S. Soeparman, D.Widhiyanuriyawan, B. Sutanto, and Suyitno, AIP Conf. Proceed., 2017, 1788, 030123, doi: $10.1155 / 2017 / 2704864$.

[26] S. Khadtare and H. Pathan, J. Renew. Sus. Ener., 2014, 6, 053131, doi: 10.1063/1.4899050.

[27] W. Chang, C. Lee, W. Yu, and C. Lin, Nano.Resea. Lett., 2012, 7, 1-10, doi: 10.1186/1556-276X-7-688.

[28] Hwang, K. Jun, W. Shim, Y. Kim, G. Kim, C. Choi, S. Ook Kang, and D. W. Cho, Phy. Chem. Chem. Phy., 2015, 17, 2197421981, doi: 10.1039/C5CP03416G.

[29] D. R. Shinde, P. S. Tambade, K. M. Gadave, K. S. Pawar, M. Naushad, and H. M. Pathan. J. Mat. Sci.: Mater. Elect., 2017, 28, 11311-11316, doi: 10.1007/s10854-017-6923-5.

[30] A. Kulkarni, M. Prasad, H. Pathan, and R. Patil, Appl. Nanosci, 2016, 6, 567-574, doi: 10.1007/s13204-015-0458-y

[31] F. Mann, B. Saunders, Practical Organic Chemistry, Pearson education, 4th Ed, 2009, New Delhi.

[32] M. Iraj, M. Kolahdouz, E. Asl-Soleimani, E. Esmaeili, and Z. Kolahdouz, J. Mater. Sci.: Mater. Electronics, 2016, 27, 64966501, doi: 10.1007/s10854-016-4591-5.

[33] E. Galoppini, Chem. Rev., 2004, 248, 1283-1297, doi: 10.1016/j.ccr.2004.03.016.

[34] S. Xuhui, C. Xinglan, T. Wanquan, W. Dong, and L. Kefei, AIP Adv., 2014, 4, 031304, doi: 10.1063/1.4863295.

[35] C. Wang, L. Yin, L. Zhang, Y. Qi, N. Lun, Langmuir, 2010, 26, 12841-12848, doi: 10.1021/la100910u.

[36] K. Yu, J. Shi, Z. Zhang, Y. Liang, and W. Liu, J. Nano., 2013, 5, 951, doi: 10.1155/2013/372951.

[37] K. Sini, S. Biswarup and M. Satyabiaa, Phys. Chem., 2014, 16, 12741-12749, doi: 10.1039/C4CP01315H.

[38] Y. Jo, K. N. Hui, K. Hui, Y. R. Cho, and K. H. Kim, Mater. Resea. Bull., 2014, 51, 345-350, doi: 10.1016/j.materresbull.2013.12.026.

[39] X. L. Zhang, K. S. Hui, F. Bin, K. N. Hui, L. Li, Y. R. Cho, R. S. Mane, and W. Zhou, Surf. Coat. Technol., 2015, 261, 149155, doi: 10.1016/j.surfcoat.2014.11.043.

[40] C. Dette, A. Miguel, P. Osorio, C. S. Kley, P. Punke, C. E. Patrick, P. Jacobson, F. Giustino, S. J. Jung and K. Kern, Nano Lett., 2014, 14, 6533-6538, doi: 10.1021/nl503131s.

[41] D. R. Shinde, P. S. Tambade, H. M. Pathan, and K. M.Gadave, Mater. Sci. Poland, 2018, 35, 746-754, doi: 10.1515/msp-20170088.

[42] A. Patil, K. Patil, S. Pardeshi, J. Haz. Mater., 2010, 183, $315-$ 323, doi: 10.1016/j.jhazmat.2010.07.026.

[43] M. Khatamiana, A. Khandara, B. Divbanda, M. Haghighib, and S. Ebrahimiaslc, J. Molecu. Cataly. A: Chem., 2012, 365, 120-127, doi: 10.1016/j.molcata.2012.08.018.

[44] X. Feng, and L. Sun, Ene. Envir. Sci., 2011, 4, 818-841, doi: 10.1039/C0EE00448K.

[45] Lin, C. Yu, Y. Lai, H. Chen, J. Chen, C. Kung, L. R. Vittal, and K. Ho, Ene. Envir. Sci., 2011, 4, 3448-3455, doi: 10.1039/C0EE00587H.

\section{Author information}

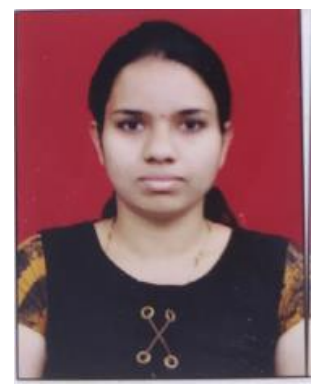

Shital S. Rakhunde received her master's degree in Analytical Chemistry and her M. Phil. degree is in chemistry from the Savitribai Phule Pune University, Pune. Title of her thesis at M. Phil. degree is $\mathrm{ZnO}$ photoanode based dye sensitized solar cell with Azo Dyes of P-amino benzoic acid with $\beta$-Napthol and 8-

Hydroxyquinoline.

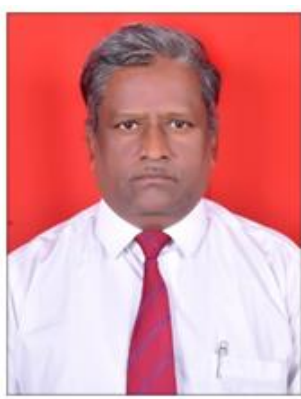

Kisan Mahadeo Gadave Received his master's degree in Inorganic Chemistry and his Ph. D. in chemistry from the Shivaji University Kolhapur, India. He joined as assistant professor to Pune Districts Education Association's B. G. College Sangvi, Pune, India and presently working at Prof. Ramkrishna More College Akurdi. Presently he is Associate professor in the same institute. He received $M$. Phil. guide recognition in chemistry from Savitribai Phule Pune University, Pune. Presently he is working on deposition of thin films and their applications in PEC cell and in DSSC.

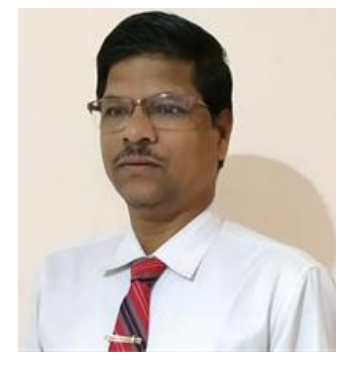

Dnyaneshwar Rambhau Shinde Received his master's degree in Inorganic Chemistry and his Ph. D. in Environmental Science from the Savitribai Phule Pune University, Pune, India. He joined as assistant professor to Prof. Ramkrishna More College Akurdi, in 1999 and now he is Associate professor in the same institute. He received Ph. D. guide recognition in chemistry from host university. Presently he is working on synthesis of nanomaterials and its applications in DSSC, photo catalysis and in gas sensing.

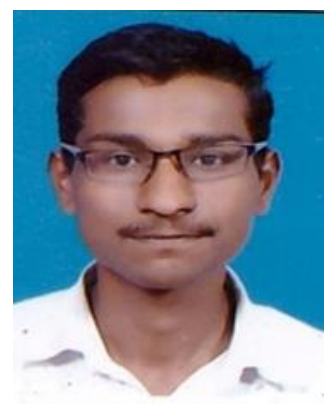

Pankaj K. Bhujbal is a research fellow in Physics at the Advanced Physics Laboratory, Department of Physics, Savitribai Phule Pune University, Pune, India with Dr. Habib M. Pathan. He received his master's degree in Physics from the Fergusson college, Pune. His research interests include Thin films, Quantum Cascade Laser and DSSCs.

Publisher's Note: Engineered Science Publisher remains neutral with regard to jurisdictional claims in published maps and institutional affiliations 